NASA/TM-2004-212976

\title{
Unsteady, Cooled Turbine Simulation Using a PC-Linux Analysis System
}

Michael G. List and Mark G. Turner

University of Cincinnati, Cincinnati, Ohio

JenPing Chen and Michael G. Remotigue

Mississippi State University, Starkville, Mississippi

Joseph P. Veres

Glenn Research Center, Cleveland, Ohio 
Since its founding, NASA has been dedicated to the advancement of aeronautics and space science. The NASA Scientific and Technical Information (STI) Program Office plays a key part in helping NASA maintain this important role.

The NASA STI Program Office is operated by Langley Research Center, the Lead Center for NASA's scientific and technical information. The NASA STI Program Office provides access to the NASA STI Database, the largest collection of aeronautical and space science STI in the world. The Program Office is also NASA's institutional mechanism for disseminating the results of its research and development activities. These results are published by NASA in the NASA STI Report Series, which includes the following report types:

- TECHNICAL PUBLICATION. Reports of completed research or a major significant phase of research that present the results of NASA programs and include extensive data or theoretical analysis. Includes compilations of significant scientific and technical data and information deemed to be of continuing reference value. NASA's counterpart of peerreviewed formal professional papers but has less stringent limitations on manuscript length and extent of graphic presentations.

- TECHNICAL MEMORANDUM. Scientific and technical findings that are preliminary or of specialized interest, e.g., quick release reports, working papers, and bibliographies that contain minimal annotation. Does not contain extensive analysis.

- CONTRACTOR REPORT. Scientific and technical findings by NASA-sponsored contractors and grantees.
- CONFERENCE PUBLICATION. Collected papers from scientific and technical conferences, symposia, seminars, or other meetings sponsored or cosponsored by NASA.

- SPECIAL PUBLICATION. Scientific, technical, or historical information from NASA programs, projects, and missions, often concerned with subjects having substantial public interest.

- TECHNICAL TRANSLATION. Englishlanguage translations of foreign scientific and technical material pertinent to NASA's mission.

Specialized services that complement the STI Program Office's diverse offerings include creating custom thesauri, building customized databases, organizing and publishing research results ... even providing videos.

For more information about the NASA STI Program Office, see the following:

- Access the NASA STI Program Home Page at http://www.sti.nasa.gov

- E-mail your question via the Internet to help@sti.nasa.gov

- Fax your question to the NASA Access Help Desk at 301-621-0134

- Telephone the NASA Access Help Desk at 301-621-0390

- Write to:

NASA Access Help Desk

NASA Center for AeroSpace Information 7121 Standard Drive

Hanover, MD 21076 
NASA/TM-2004-212976

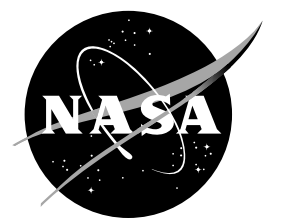

\section{Unsteady, Cooled Turbine Simulation Using a PC-Linux Analysis System}

Michael G. List and Mark G. Turner

University of Cincinnati, Cincinnati, Ohio

JenPing Chen and Michael G. Remotigue

Mississippi State University, Starkville, Mississippi

Joseph P. Veres

Glenn Research Center, Cleveland, Ohio

Prepared for the

42nd Aerospace Sciences Meeting and Exhibit

sponsored by the American Institute of Aeronautics and Astronautics

Reno, Nevada, January 5-8, 2004

National Aeronautics and

Space Administration

Glenn Research Center 


\section{Acknowledgments}

The authors wish to thank the support received from the Numerical Propulsion System Simulation Program (NPSS), the Aerospace Propulsion and Power Program at NASA Glenn Research Center, and the Computing, Information and Communications Technology Program (CICT). The authors are also very appreciative to

GE Aircraft Engines for continued interest in the simulation of the GE90.

This report contains preliminary

findings, subject to revision as analysis proceeds.

Trade names or manufacturers' names are used in this report for identification only. This usage does not constitute an official endorsement, either expressed or implied, by the National

Aeronautics and Space Administration.

Available from

NASA Center for Aerospace Information 7121 Standard Drive

Hanover, MD 21076
National Technical Information Service 5285 Port Royal Road Springfield, VA 22100 


\title{
Unsteady, Cooled Turbine Simulation Using a PC-Linux Analysis System
}

\author{
Michael G. List and Mark G. Turner \\ University of Cincinnati \\ Cincinnati, Ohio 45220 \\ JenPing Chen and Michael G. Remotigue \\ Mississippi State University \\ Starkville, Mississippi 39762 \\ Joseph P. Veres \\ National Aeronautics and Space Administration \\ Glenn Research Center \\ Cleveland, Ohio 44135
}

\section{Summary}

The first stage of the high-pressure turbine (HPT) of the GE90 engine was simulated with a threedimensional unsteady Navier-Sokes solver, MSU Turbo, which uses source terms to simulate the cooling flows. In addition to the solver, its pre-processor, GUMBO, and a post-processing and visualization tool, Turbomachinery Visual3 (TV3) were run in a Linux environment to carry out the simulation and analysis. The solver was run both with and without cooling. The introduction of cooling flow on the blade surfaces, case, and hub and its effects on both rotor-vane interaction as well as the effects on the blades themselves were the principle motivations for this study. The studies of the cooling flow show the large amount of unsteadiness in the turbine and the corresponding hot streak migration phenomenon. This research on the GE90 turbomachinery has also led to a procedure for running unsteady, cooled turbine analysis on commodity PC's running the Linux operating system.

\section{Introduction}

The GE90-94B is a production engine offered on the Boeing 777-200ER as shown in a cutaway schematic in figure 1 . It is a $94000 \mathrm{lb}$ thrust version of the GE90 with a bypass ratio of 8.4. This engine is the emphasis of research presented by Turner et al. (2000, 2001, and 2002) in which the entire engine is modeled at a takeoff condition - the turbomachinery with the Average Passage Code as described by Adamczyk et al. (1986 and 2000) and Kirtley et al. (1999), and the combustor analyzed with the National Combustor Code as described by Liu (2001). The entire turbine, both high-pressure turbine (HPT) and low-pressure turbines (LPT) were analyzed and presented by Turner et al. (1999). In that paper, the steady Average Passage Simulation was used to simulate the GE90 HPT rig, the LPT rig, and the combined HPT and LPT at takeoff conditions.

The effort of this paper is to demonstrate an increase of fidelity of the modeling of the HPT to include unsteady analysis as part of future efforts of multifidelity full engine simulations. The Average Passage Approach includes much of the multistage physics, but some of the details of the unsteadiness are still not modeled well. Hot Streak Migration as presented by Kerrebrock and Mikolajczak (1970), Orkwis et al. (2002), Busby et al. (1999), and Sondak et al. (1996) is truly an unsteady phenomenon. In addition, blockage due to wakes and blunt leading edges, entropy production and wake mixing are driven by unsteady three-dimensional effects. For a cooled turbine nozzle at takeoff conditions, the tangential variation of total temperature alone is over $1000^{\circ} \mathrm{R}$. This tangential variation is driving some very interesting unsteady flow physics that are best captured with an unsteady solver.

The HPT has two stages comprising four blade rows, the first two of which were investigated here. There are 40 stage- 1 vanes and 68 stage- 1 rotor blades around the annulus. A phase lagged boundary condition, available in MSU Turbo, has been utilized to obtain the correct phase without changing the geometry. The only approximation with this model is an assumption of periodicity in a quarter of the annulus. 
In the past, very expensive computers have been needed to run and post process an unsteady simulation. Because the Linux operating system is so versatile, and because it runs effectively (especially using MPI in parallel) on commodity processors, it was used as the primary computer operating system for this research.

This paper will briefly explain the process used to set up and run multiple blade row calculations with the unsteady solver. Results of the uncooled and cooled cases are then presented.

\section{Analysis Tools}

A graphical pre-processor described by Remotigue (2002) was used to block the grid files, incorporate source terms, and adjust the boundary conditions. The Graphical Unstructured-MultiBlock Omnitool (GUMBO) was developed at Mississippi State to prepare grids for parallel computation in TURBO. Figure 2 shows the grid used for the rotor (the nozzle grid is similar). It is the same grid as used in the average passage simulation presented by Turner (1999) except in this case no overlapping grids are employed. The grids are fine enough for Turbo, especially around the trailing edges of the nozzle and rotor. Wall functions have been used, so detailed boundary layer grids are not needed. Once loaded into GUMBO, the grids and source terms were manipulated. Figure 3 shows the cooling holes for the nozzle and rotor grids loaded into GUMBO, and figure 4 shows a blocking decomposition that was used in an initial simulation. A principle purpose for the development of GUMBO was to help eliminate human error through the generation of appropriate boundary conditions and a graphical display of the selected volumes and boundaries. The output of the pre-processing step included the decomposed grid domains, the decomposed, steady solution files, a file with all physical boundary information, a connectivity file, and data for sliding interface locations used by the phase-lag approximation.

The unsteady solver used in the analysis is described by Chen, et al. (2001). MSU TURBO (Parallel Turbo v3.0) is a parallel version of the original, serial Turbomachinery analysis tool developed at Mississippi State. The solver was chosen because of its capabilities. Required for the analyses being performed were the unsteady blade row interaction, phase-lag approximation abilities, source term capability to simulate cooling flows, and a variable $\gamma$ capability because the air-combustion products mixture is not a perfect gas. The solution algorithm is an iterative, implicit, timeaccurate scheme with characteristics-based finitevolume spatial discretization.

Post-processing and investigation have primarily been done in Turbomachinery Visual3 (TV3), a code that uses the Visual3 library developed by Haimes and Giles (1991). An unsteady version of this has been developed which enables multiple flow files to be displayed, creating an interactive movie in time. Having gained the ability to view an entire period through the enhancement, TV3 has become an effective tool in the post-processing of turbomachinery applications. Several other modifications have been made including the accounting for variable $\gamma$ in the post processing. Also, TV3 can generate profiles at any points for all of the scalars for which it solves. These abilities make TV3 perfect for multiple stage turbine simulations with unsteady flow.

\section{Approach}

Using the codes from Mississippi State it was possible to develop a process for preparing and running a multirow and multistage calculation.

The generation of vstage (APNASA version 1 format) grid and initial flow files was completed by using the solutions and grids from previously run average-passage models in HDF format and a simple converter tool. The initial solutions were steady state models for each blade row. Information files were created for each blade row containing pertinent data on leading edge and trailing edge locations, hub and tip clearance, and number of blades in the full annulus. GUMBO's associated post-processing tools, Locate and Merge, require this data to rebuild the initial grid and to build the final blade row solutions. Source Term Program (STP) is the tool to create steady sources applied to the control volumes next to the wall to represent the effect of cooling flow. The application is more completely described by Hunter (1998), Turner and Saeidi (1997), and Turner et al. (1999). STP was run to create lists of source terms for the hub, case, and blades of each row. The lists were concatenated by a small Fortran program, which also formatted them for GUMBO. 
The pre-processor was run to prepare the grids for parallel computation. Blocking was completed to meet size and time requirements; the most efficient and least resource-demanding scheme was 8 blocks per blade row. The desired boundary conditions were applied and the TURBO case files were generated. User input files were written based on experimental data from the combustor and the parameters used for averagepassage runs. Temperature, pressure, and flow angle profiles were specified at the inlet, and an average static pressure profile was given for the exit. Reference conditions such as $\gamma$ and temperature tables, pressures, etc. were set based on APNASA reference values. With the case built, the files were transferred to the Linux cluster and TURBO was run.

Once the solver began iteration, convergence to a periodic solution was monitored using Microsoft ${ }^{\circledR}$ Excel. A simple program was also written to run Fast Fourier Transforms on any of the output histories of TURBO. Once the periodic solution was obtained, the Locate and Merge utilities were used. The result of this process was the rebuilt grid files and corresponding solution files for each blade row. These files were then read into TecPlot and TV3 for analysis. Another postprocessing tool, APNASACAT, was also used to created mass averaged profiles.

\section{HP1 (Uncooled Simulation)}

In attempting to learn more about GUMBO and MSUTurbo and their interactions, HP1 was built as a test case. After learning to use GUMBO the rotor and the stator were separated into two blocks each. Boundary conditions were applied and the associated files were saved. Originally no source files had been generated for this case, so the files input00, input01, and input02 were borrowed directly from a sample case without modification and used in MSUTurbo to generate distance mapping files. This initial sampling of the code was used to complete one of the slightly time consuming processes in TURBO, and to ensure that all of the parallel components, including the Message Passing Interface (MPI), were properly established. Distance calculations were completed, and the solver expectedly failed to iterate. Changes were made to the input files to preserve radial equilibrium, use appropriate reference conditions, use an inlet profile generated from combustor simulation output, and use a backpressure for a radial equilibrium exit boundary condition.
Four blocks were used for this uncooled simulation. The new flow files were created and several runs of the case were submitted on two heterogeneous dualprocessor machines at the University of Cincinnati. This case ran stably without cooling flow and iteration time was approximately 115 to $130 \mathrm{sec}$ per iteration. Starting with a general, steady solution, approximately 4 complete periods were needed to iterate to a fully periodic flow.

The grid was then further decomposed into 16 blocks. The case was run to a periodic solution on the NASA Linux cluster, Aeroshark. The boundary condition for the exit of the rotor was changed from "radial equilibrium" to "pressure exit." An average pressure profile at the exit was specified to hold the pressures to downstream experimental measurements.

Many minor modifications were made to the case to provide faster convergence to a periodic solution. Figure 4 shows the blocking used for one of the uncooled checkout cases. Each blade row was divided four times axially, and once radially. This blocking scheme was chosen to determine the effects on code performance. During the runs it was noticed that because there were now four blocks at the sliding interface, iteration time increased slightly (about 10 percent).

\section{HP2 (Cooled Simulation)}

HP2 included nozzle 1 and rotor 1 and was expanded to include more grid points axially in front of the nozzle. Also, all divisions while creating the 16 blocks were made axially. This allowed a better picture of what was occurring at the inlet to the nozzle and the monitoring of a clipping issue. The source terms were created for input to GUMBO and double-checked for accuracy.

The files were moved to a NASA Linux cluster for the execution of Turbo. Using 16 processors on the Linux cluster, Aeroshark, the code was run for multiple periods. Once a separation, initially present (which caused some of the clipping and many problems in HP1), was blown out, the temperature and pressure profiles were modified to reflect their true values. The final restart began with no problem and there were immediate adjustments in the flow. With 16 blocks a 400 percent speed up was seen over the original, uncooled investigation with only 4 blocks (several percent due to the improved network and consistent 
CPU speeds). It was taking $26 \mathrm{sec}$ per iteration (time step) on the AMD 2000+ processors. The parallel efficiency averaged 93.2 percent, as compared to 87 percent for HP1 on the heterogeneous machines. Future grids may be further divided during blocking to further increase speed. Critical investigation of the mass flow rates, pressures and temperatures ensued and were compared with values obtained using APNASA solutions. The convergence history of the mass flow rate is shown in figure 5. The periodicity of the exit flow can be seen along with the presence of multiple frequencies. The inlet, sliding-interface boundary, and exit mass flows converged and remained periodic.

The unsteady effects of the rotor on the vane are small for this subsonic stage. Because of the motion of the rotor, some unsteadiness occurs in the nozzle, but there is not much direct, significant pressure interaction visible. Only a small-scale pressure was observed buffeting the trailing edge of the nozzle blade (less than 2 percent of the total pressure). Figure 6 shows the effect of the rotor leading edge on the shape of the nozzle wake.

\section{Results}

As mentioned, the solutions have been compared with the APNASA multistage simulations that had been calibrated to rig data and engine data. Overall quantities such as flow function, stage reaction and work were in agreement so the case was felt to be set up and run correctly. The cooling flows that were introduced have had the expected effect on the total enthalpy, as can be seen in the wake of the nozzle (figs. 6 and 7). The maximum temperatures for both cases occur at 60 percent span in the nozzle and near the case in the rotor. The hub has a large amount of cooling flow in the platform and due to cavity purge. Figure 8 shows (through the total enthalpy) the cooling holes at the nozzle hub surface.

Figures 9 to 14 are contour plots of the results in the rotor. Figure 9 shows an instantaneous plot of the total temperature at mid-span. The cold nozzle wakes can be seen as they get distorted in the rotor passage. Also clearly seen is the cold rotor wake due to the trailing edge cooling on the blade. Figure 10 shows a different instant in time showing the radial vorticity at mid-span. The incoming nozzle wake is clearly shown as well as shed vortex pairs from the trailing edge. The effect of shedding can also be seen in figure 11 in a contour plot of Rothalpy at mid-span.

Rothalpy is a quantity defined as

$$
I=h+\frac{V^{2}}{2}-\omega r V_{\theta}
$$

where $I$ is the Rothalpy, $h$ is the static enthalpy, $V$ is the absolute velocity, $\omega$ is the wheel speed, $r$ is the radius, and $V_{\theta}$ is the angular velocity. As presented by Lyman (1992), Rothalpy has properties in a rotor similar to total enthalpy in a nozzle. It is conserved on a steady streamline in inviscid flow. As such it is a useful quantity to observe in an unsteady simulation.

The density contour is shown in figure 12 . As can be seen, the incoming cold wakes are much denser than the surrounding fluid.

In this simulation and analysis, the fluid is treated as an ideal, but imperfect gas. The ratio of specific heats, $\gamma$, is modeled as a linear function of temperature. This is a good approximation although the gas constant, $R$, is a constant in this simulation and analysis, whereas in reality the products of combustion vary in span out of the combustor and have a different molecular weight than pure air which is used as the cooling flow. Figure 13 shows a snapshot in time of the variable $\gamma$ contours. It varies from lower than 1.27 for the hot fluid to greater than 1.31 for the colder fluid. This is far from a perfect gas.

Figure 14 shows the Rothalpy based on the timeaveraged solution for an entire quarter annulus period (10 nozzles and 17 rotors) at mid-span and a crossflow plane. The segregation blade-to-blade with a green (colder) streak in the middle is due to the hot streak migration effect. In the crossflow plane, this is also seen, but the strong radial profile and cooling flows are also evident.

Figures 15 to 17 show the radial profiles of total pressure, total temperature and turbulence intensity, respectively for the circumferentially mass averaged and time averaged solution. Both the cooled and uncooled simulations are presented. The inlet total pressure for the uncooled case was lowered as shown to run the stage more consistently relative to the cooled case. The inlet total temperature was kept the same. The effects of cooling and work are shown in these plots and it is apparent that the cooling effects are dramatic and cannot be ignored. It even affects the level of turbulence as shown in figure 17 . 


\section{Conclusions}

Two unsteady three-dimensional simulations have been presented: one cooled and one uncooled for the first stage of the GE90 high-pressure turbine. The process of using the system consisting of the preprocessor, GUMBO, the solver, MSU Turbo, and the postprocessor, TV3, has been described, all of which run on commodity PC's using the Linux operating system. The flow physics of the effects of unsteadiness for the cooled turbine stage have been demonstrated and explained.

\section{Future Research}

Current work is being done to analyze a threeblade row case: the stage- 1 rotor, stage- 2 nozzle and stage- 2 rotor. This is an effort to further analyze the unsteady temperature and pressure effects of the downstream rotor described in this paper upon the next stage in the HPT. Also, some effort will be devoted to the unsteady analysis of tip gaps. Intertwined in this is a need for a more advanced post-processing environment. The post-processing tool, TV3 is being expanded to allow multiple blade rows and mutiblocks, each with a different angular velocity, to be plotted and rotated while displaying unsteady flows.

\section{References}

Adamczyk, J.J., Mulac, R.A., and Celestina, M.L., "A Model for Closing the Inviscid Form of the AveragePassage Equation System," Journal of Turbomachinery, Vol. 108, pp. 180-186, 1986.

Adamczyk, J.J., "Aerodynamic Analysis of Multistage Turbomachinery Flows in Support of Aerodynamic Design," Journal of Turbomachinery, April 2000, Vol. 122, Issue 2 pp. 189-217.

Adamczyk, J.J., Celestina, M., and Chen, J.P., "WakeInduced Unsteady Flows: Their Impact on Rotor Performance and Wake Rectification," Journal of Turbomachinery, Vol. 118 No.1, pp. 88-95, January 1996.

Barter, J.W., Vitt P.H., and Chen, J.P., "Interaction Effects in a Transonic Turbine Stage," ASME-2000 GT-0376, May 2000.
Busby, J., Sondak, D. Staubach, B. and Davis, R.L., "Deterministic Stress Modeling of Hot Gas Segregation in a Turbine," ASME Paper 99-GT-076, Indianapolis, IN, June, 1999.

Chen, J.P., Barter, J.W., "Comparison of TimeAccurate Calculations for The Unsteady Interaction in Turbomachinery Stage,” AIAA-98-3292, July 1998.

Chen, J.P., and Briley W.R., "A Parallel Flow Slover for Unsteady Multiple Blade Row Turbomachinery Simulations," ASME-2001-GT-0348, June 2001.

Chen, J.P., and Whitfield, D.L., "Navier-Stokes Calculations for the Unsteady Flowfield of Turbomachinery," AIAA-93-0676, January 1993.

Chen, J.P., Celestina, M., and Adamczyk, J.J., "A new Procedure for Simulating Unsteady Flows Through Turbomachinery Blade Passage," ASME-94-GT-151. June 1994.

Haimes, Robert, and Michael Giles, "Visual3: Interactive Unsteady Unstructured 3D Visualization," AIAA Paper 91-0794, Reno NV, Jan. 1991.

Hunter, S.D., "Source Term Modeling of Endwall Cavity Flow Effects on Gaspath Aerodynamics in an Axial Flow Turbine," Ph.D. Thesis, University of Cincinnati, Department of Aerospace Engineering and Engineering Mechanics, November, 1998.

Janus, J.M. and Whitfield, D.L., "A Simple TimeAccurate Turbomachinery Algorithm with Numerical Solutions of an Uneven Blade Count Configuration," AIAA-89-0206, January 1989.

Kerrebrock, J.L. and Mikolajczak, A.A., "Intra-Stator Transport of Rotor Wakes and Its Effect on Compressor Performance," Journal of Engineering for Power, Vol. 92, No. 4, October, 1970, pp. 359-368.

Kirtley, K.R., Turner, M.G., and Saeidi, S. "An Average Passage Closure Model for General Meshes," ASME 99-GT-077, June, 1999.

Liu, N.-S., "On the Comprehensive Modeling and Simulation of Combustion Systems," AIAA 20010805, Jan. 2001, Reno, NV. 
Lyman, F.A., "On the Conservation of Rothalpy in Turbomachines," ASME 92-GT-217, 1992.

Orkwis, Paul D., Mark G. Turner, and John W. Barter, "Linear Deterministic Source Terms For Hot Streak Simulations," AIAA Journal of Propulsion and Power, Vol. 18, No. 2, pp. 383-389, March-April, 2002.

Remotigue, M.G., "A Pre-Processing System for Structured Multi-Block Parallel Computations," Numerical Grid Generation in Computational Field Simulations. Proceedings of the 8th International Conference held at Honolulu, Hawaii, June 2002.

Remotigue, M.G., "Structured Grid Technology to Enable Flow Simulation in an Integrated System Environment," Ph.D. Dissertation, Mississippi State University, MS, December 1999.

Sondak, D.L., Dorney, J.J. and Davis, R.L., "Modeling Turbomachinery Unsteadiness with Lumped Deterministic Stresses," AIAA Paper 96-2570.

Turner, M.G., "Multistage Turbine Simulations With Vortex-Blade Interaction," Journal of Turbomachinery, Vol. 118 No.4, pp. 643-653, October 1996.

Turner, M.G., and Saeidi, S. "Average Passage Code Development and Validation," Contract Report, Contract NAS3-26617, Task Order No. 57, Dec. 31, 1997.
Turner, M.G., Paul H. Vitt, David A. Topp, Sohrab Saeidi, Scott D. Hunter, Lyle D. Dailey, and Timothy A. Beach, "Multistage Simulations of the GE90 Turbine," ASME 99-GT-98, June 1999.

Turner, M.G., "Full 3D Analysis of the GE90 Turbofan Primary Flowpath," NASA/CR-2000-209951, March 2000.

Turner, M.G., Rob Ryder, Andrew Norris, Mark Celestina, Jeff Moder, Nan-Suey Liu, John Adamczyk and Joe Veres, "High Fidelity 3D Turbofan Engine Simulation with Emphasis on Turbomachinery-Combustor Coupling," AIAA-2002-3769, July 2002.

Turner, M.G., Andrew Norris, and Joe Veres, "High Fidelity 3D Simulation of the GE90," AIAA-2003-3996, Orlando, FL, June 2003.

Whitfield, D.L., Swafford, T.W., Janus, J.M., Mulac, R.A, and Belk, D.M., "Three-Dimensional Unsteady Euler Equations Solution for Propfans and CounterRotating Propfans in Transonic Flow," AIAA-871197, June 1987.

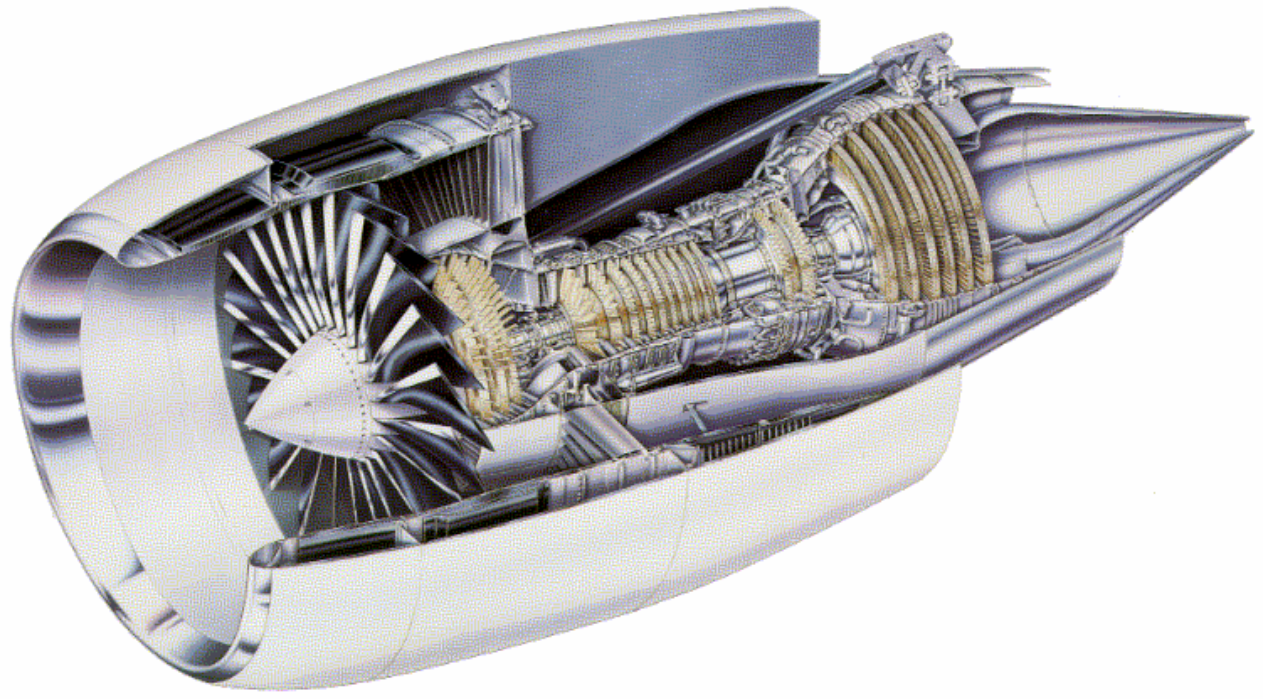

Figure 1. GE 90 Turbofan Engine schematic. 


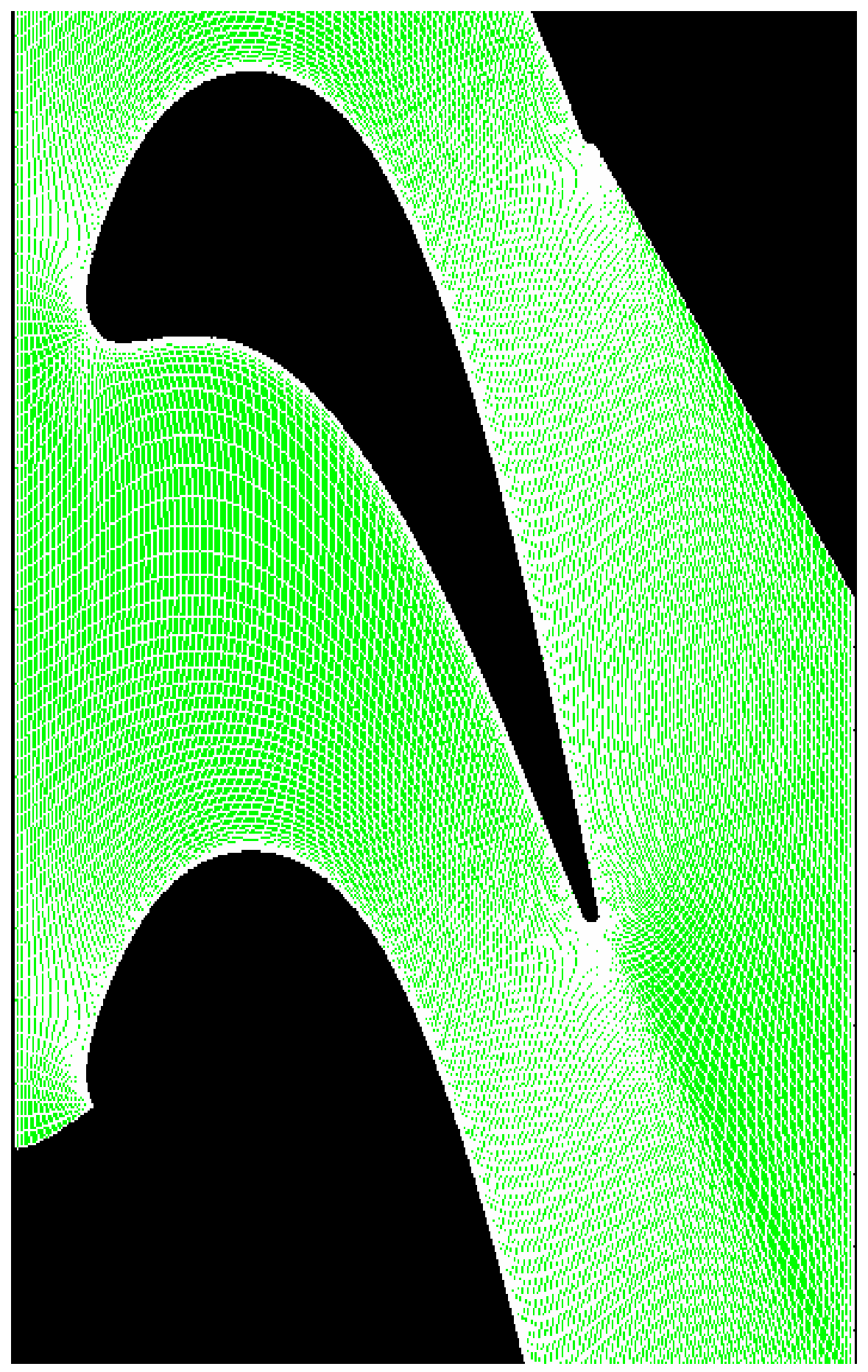

Figure 2. Grid for HPT rotor. 


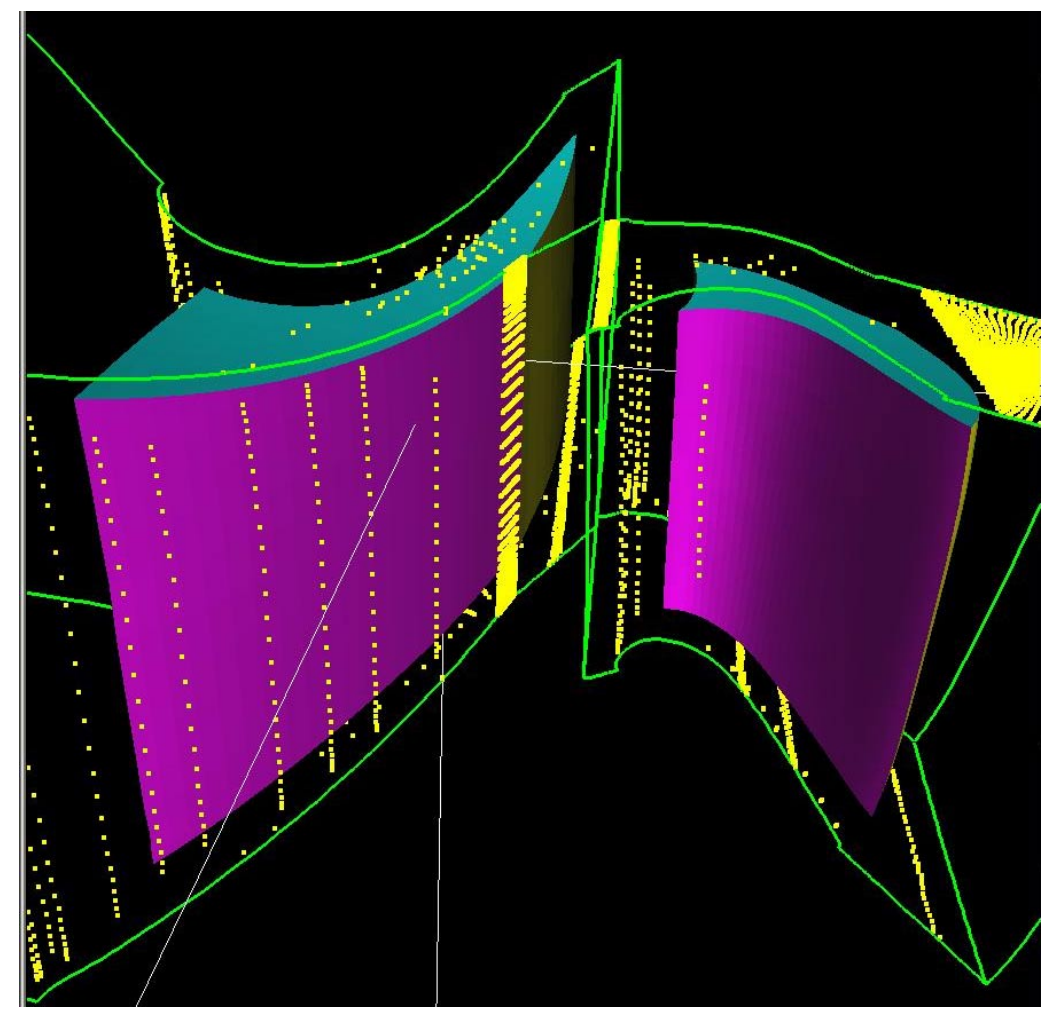

Figure 3. Source Term locations (cooling holes) displayed in GUMBO.

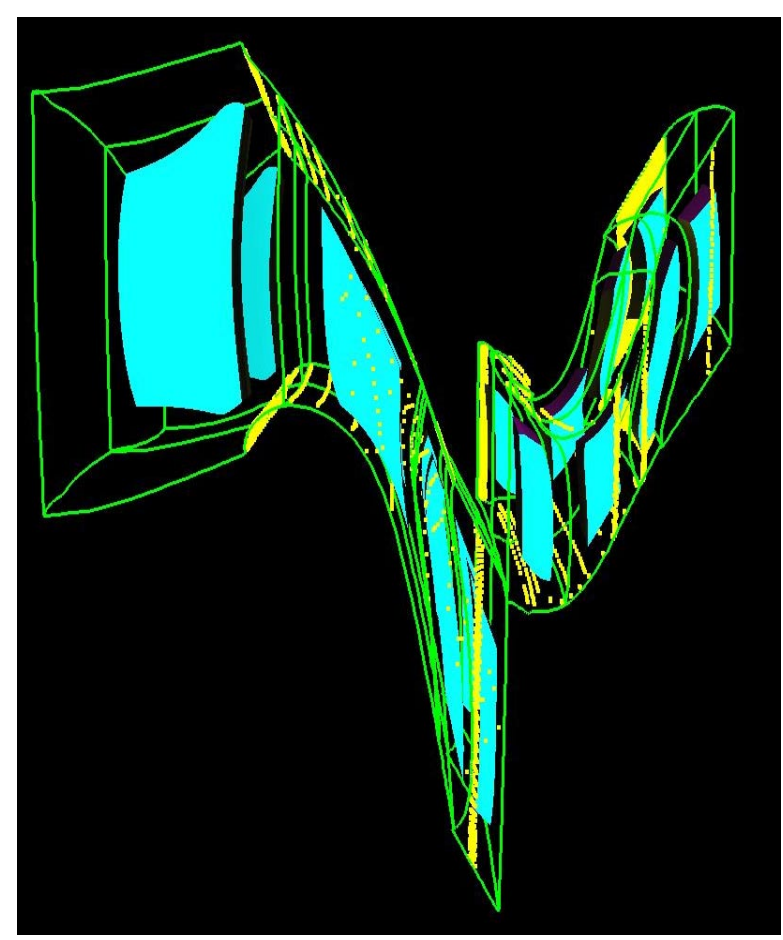

Figure 4. Blocking by GUMBO. 


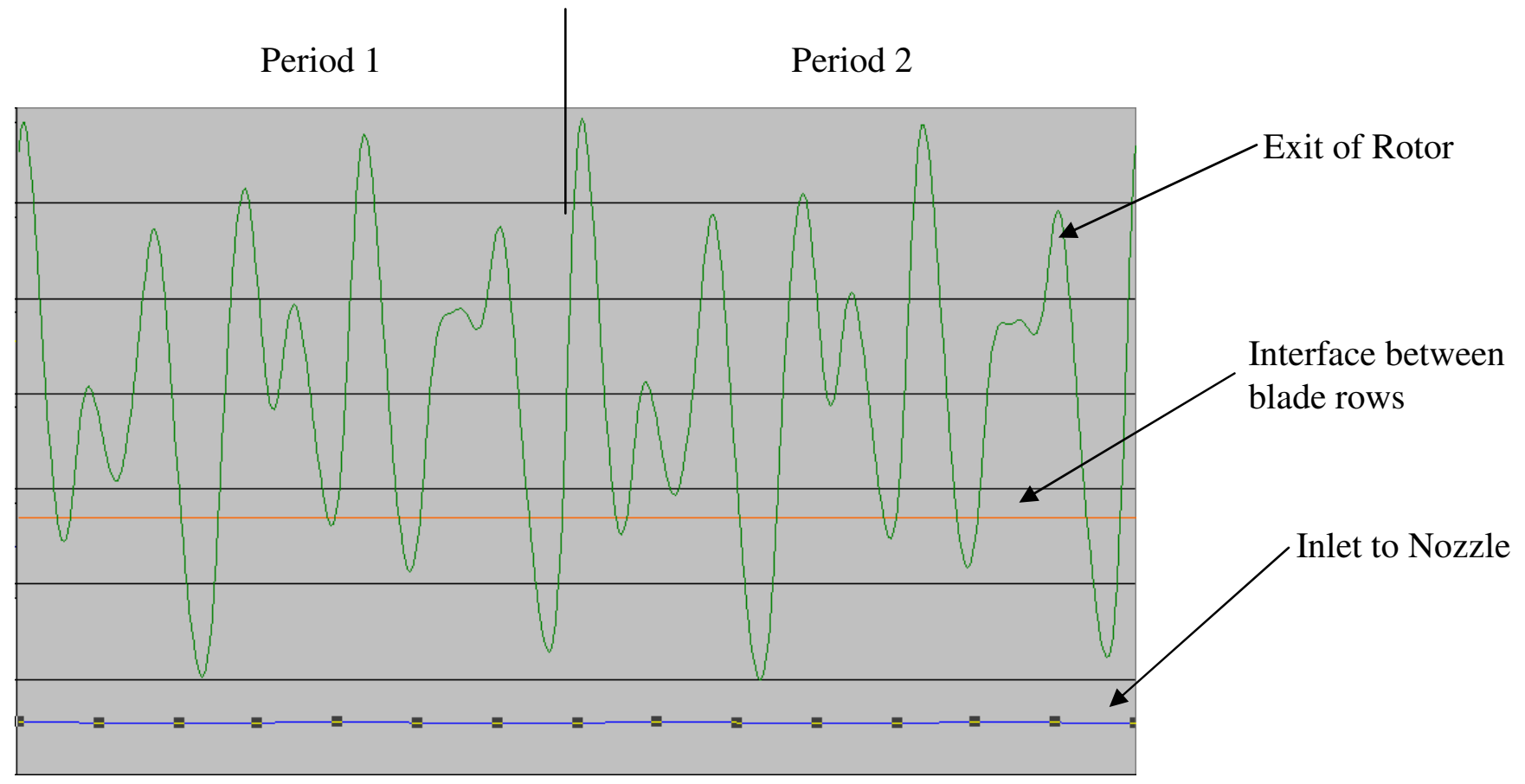

Figure 5. Mass flow rate history for two nozzle passing periods. 


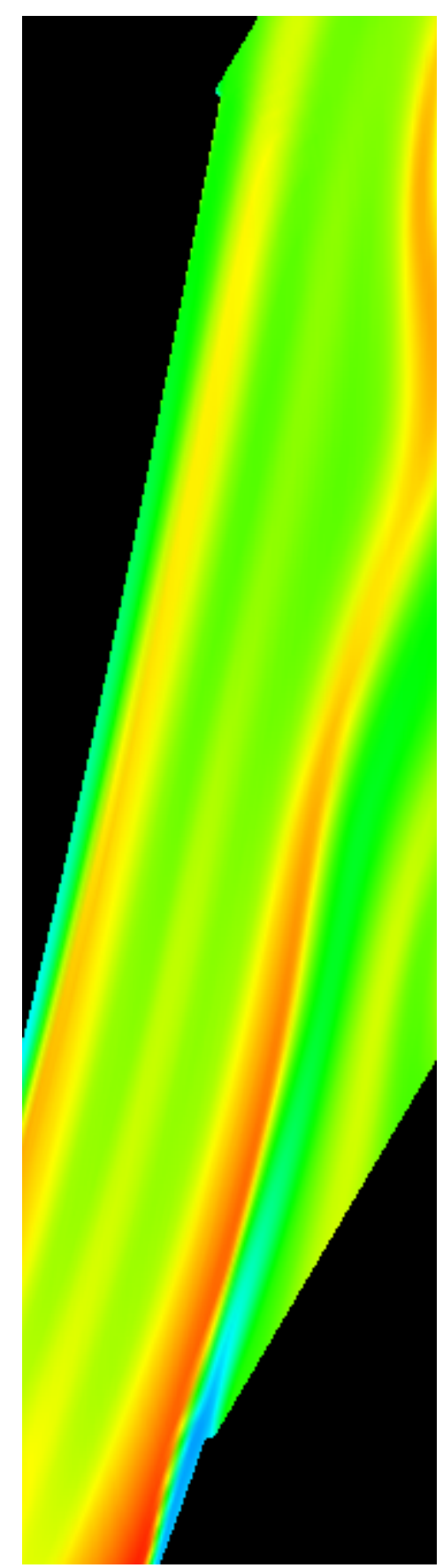

Figure 6. Total Enthalpy contours at mid-span of the nozzle for the cooled case. Wake unsteadiness due to rotor leading edge can be seen.

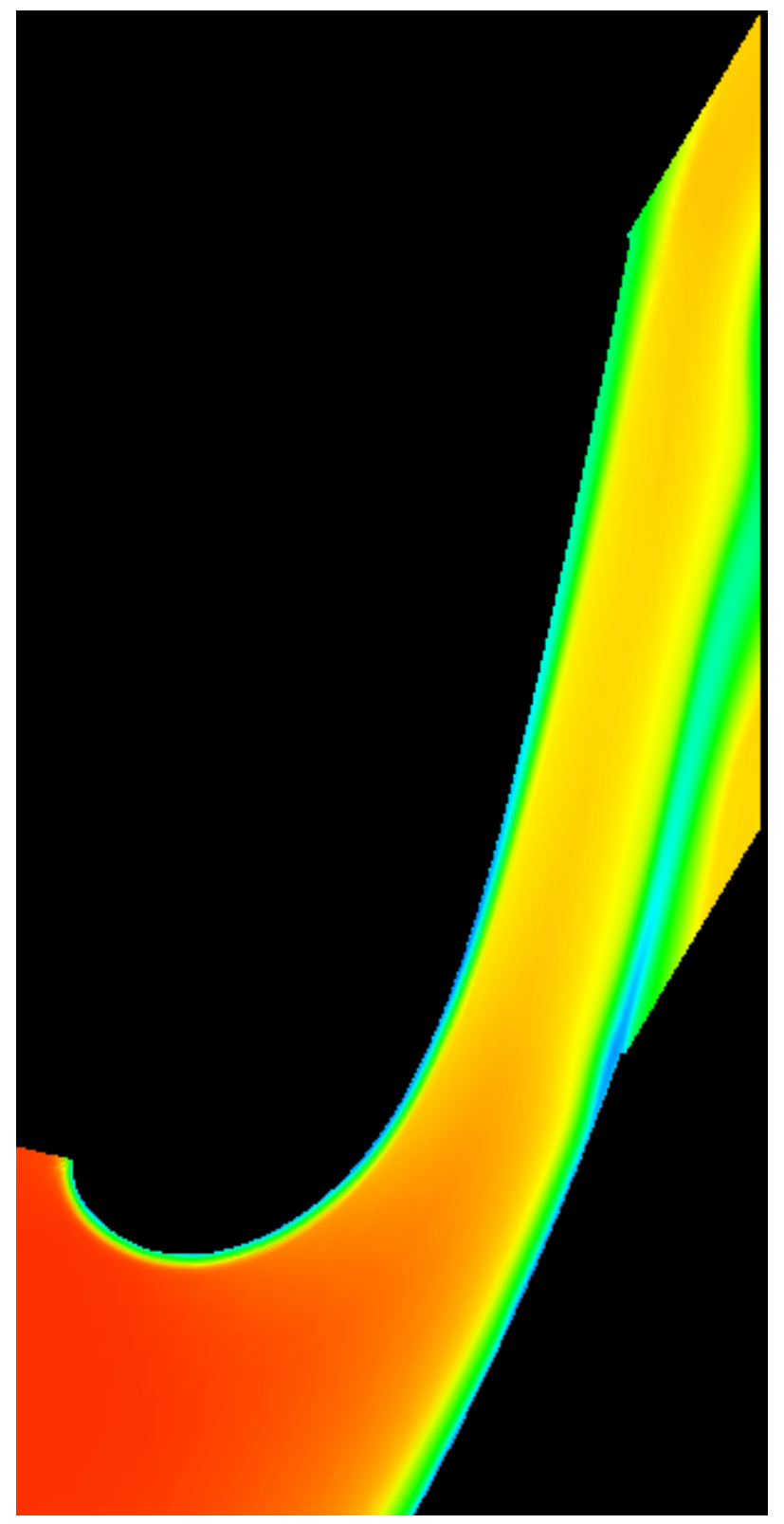

Figure 7. Instantaneous Total Enthalpy contours of nozzle 1 at mid-span. Cooled wake is clearly visible. 


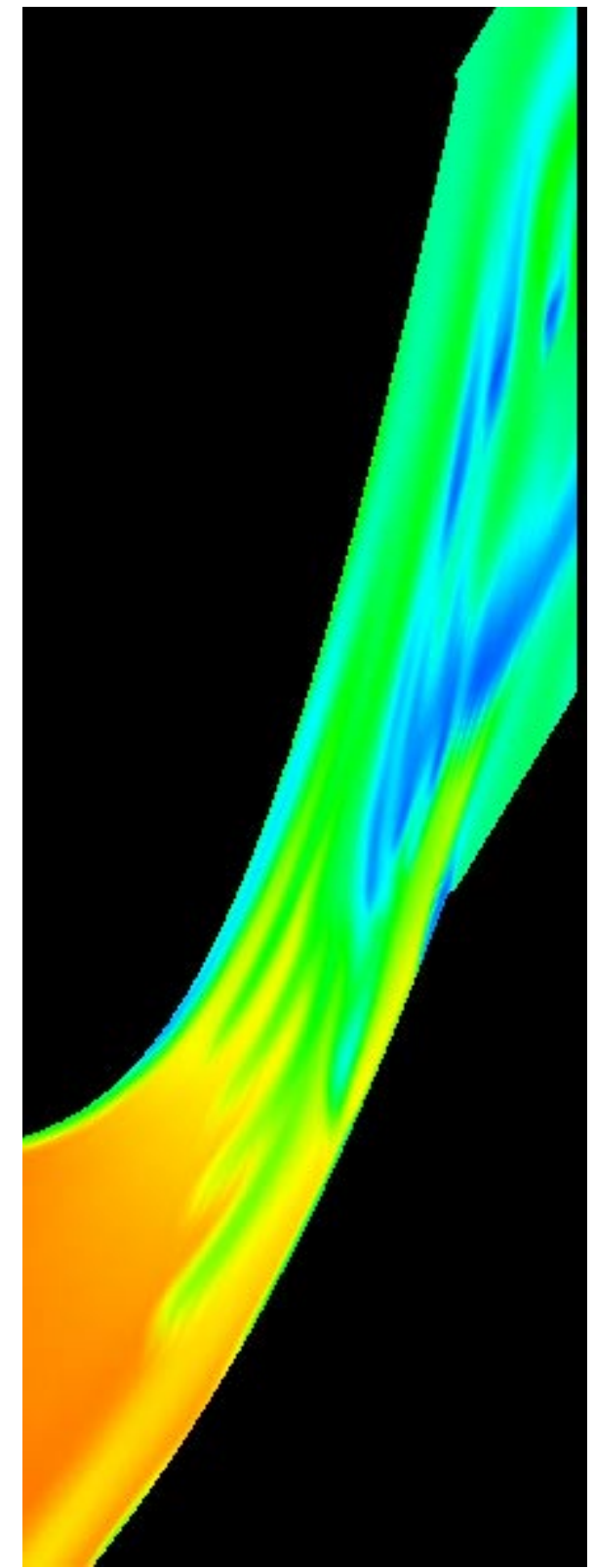

Figure 8. Total Enthalpy contours near the hub in the vane showing platform cooling.

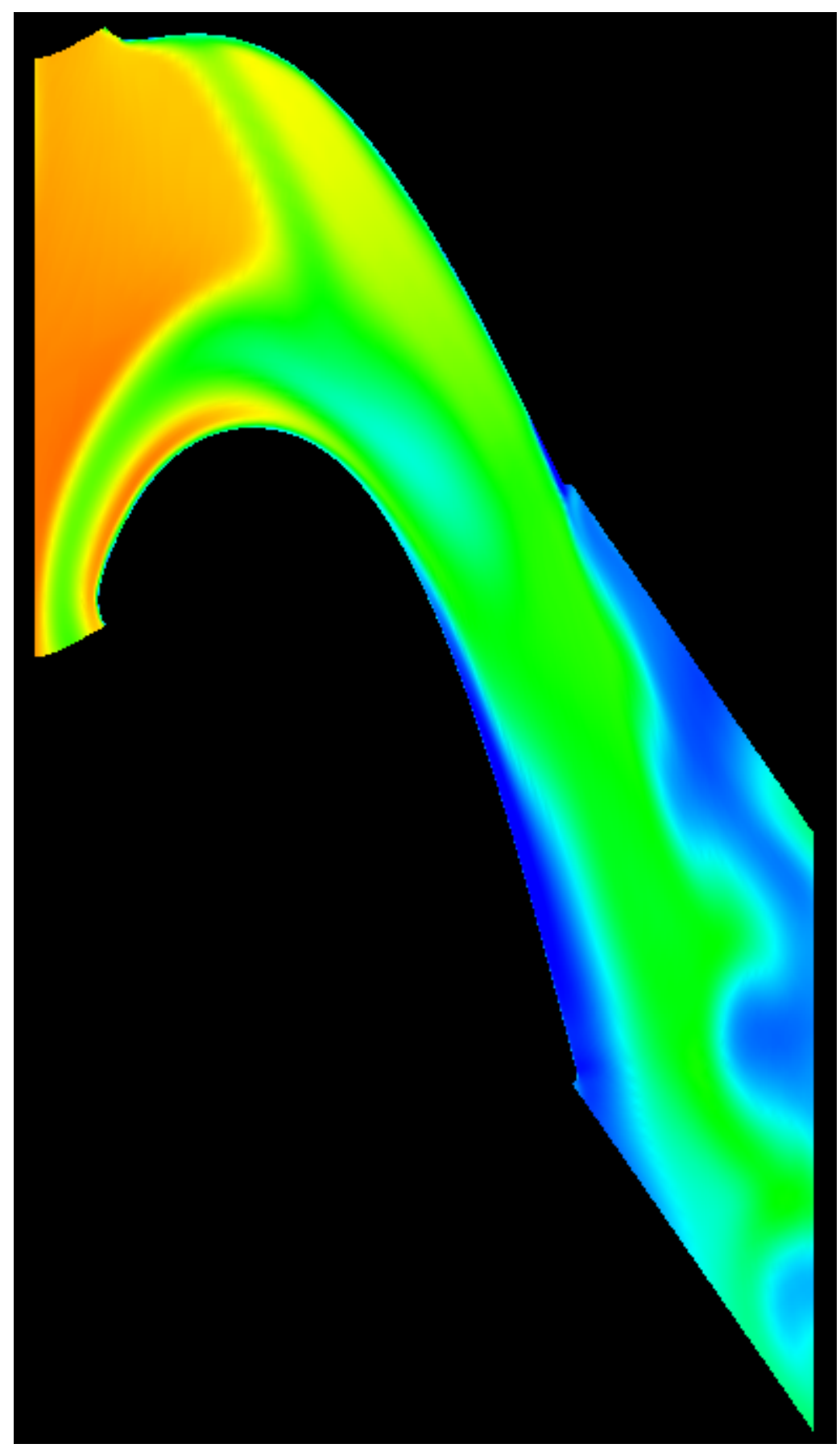

Figure 9. Total Temperature contours in rotor at mid-span, showing effect of cooling flow in turbine. 


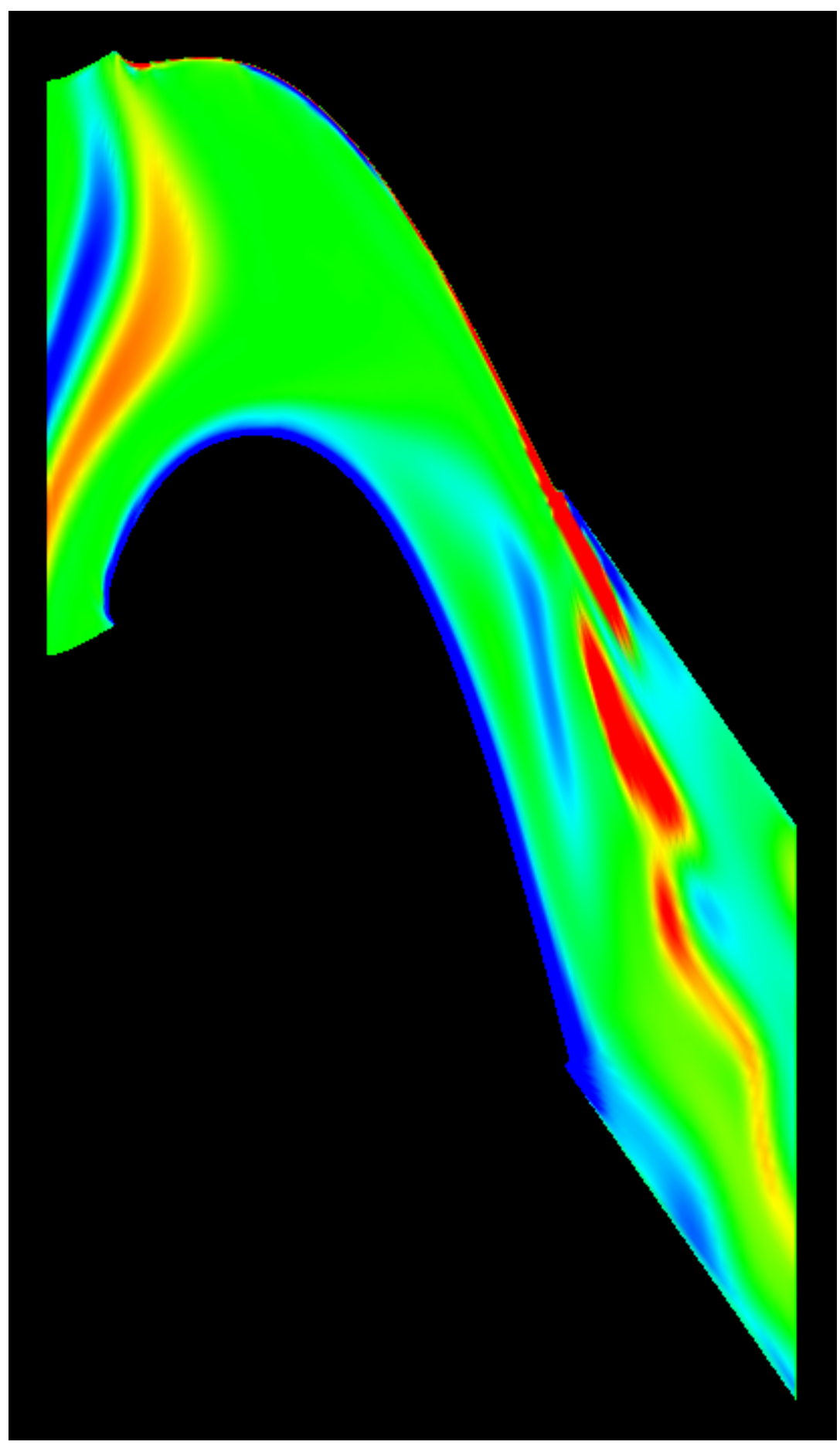

Figure 10. Radial Vorticity contours at the mid-span of the cooled rotor. The incoming nozzle wakes and the effects of shedding of the rotor wake can be seen. 


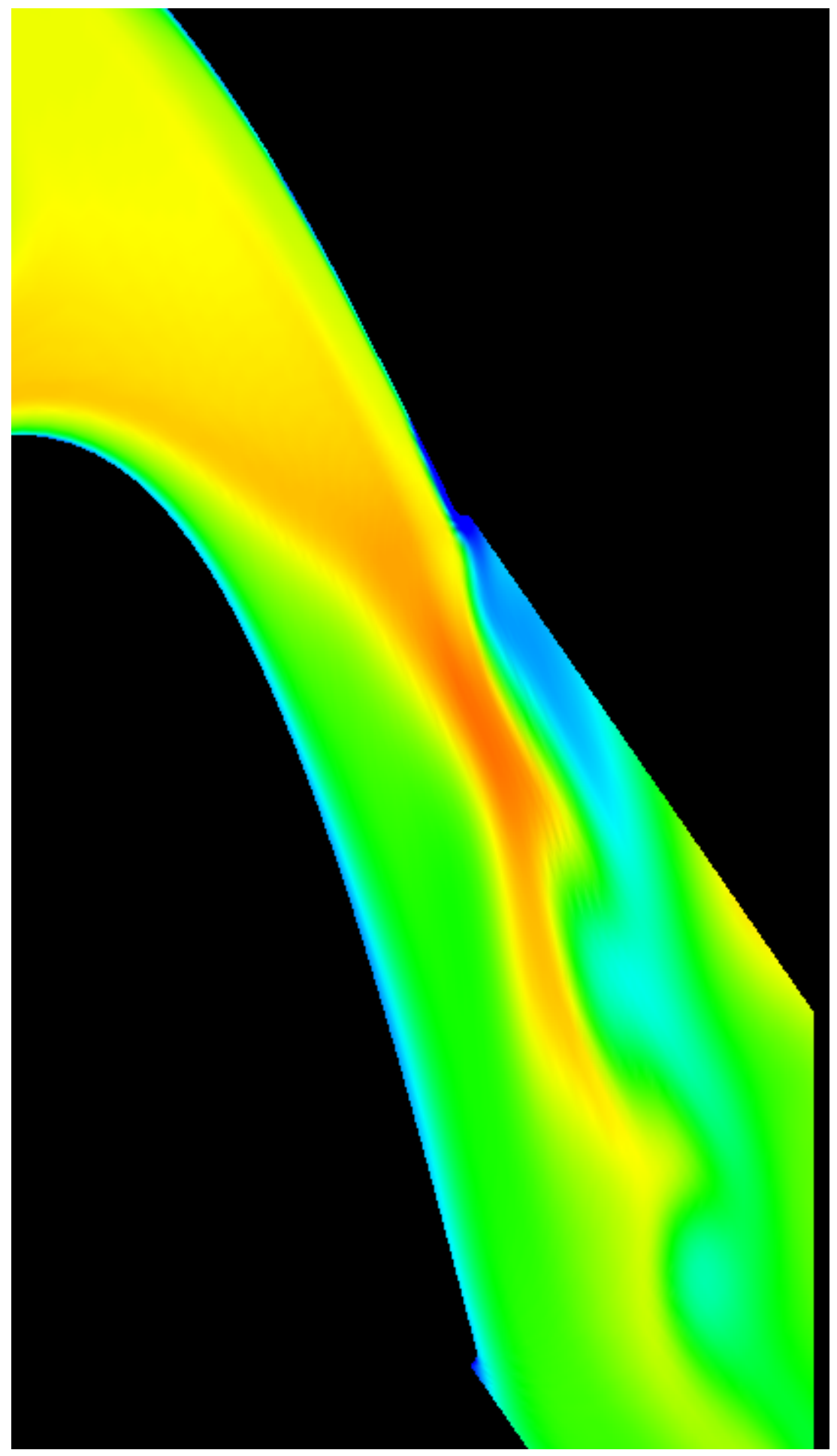

Figure 11. Rothalpy contours at the midspan of the cooled rotor near the trailing edge, showing the effects of shedding. 


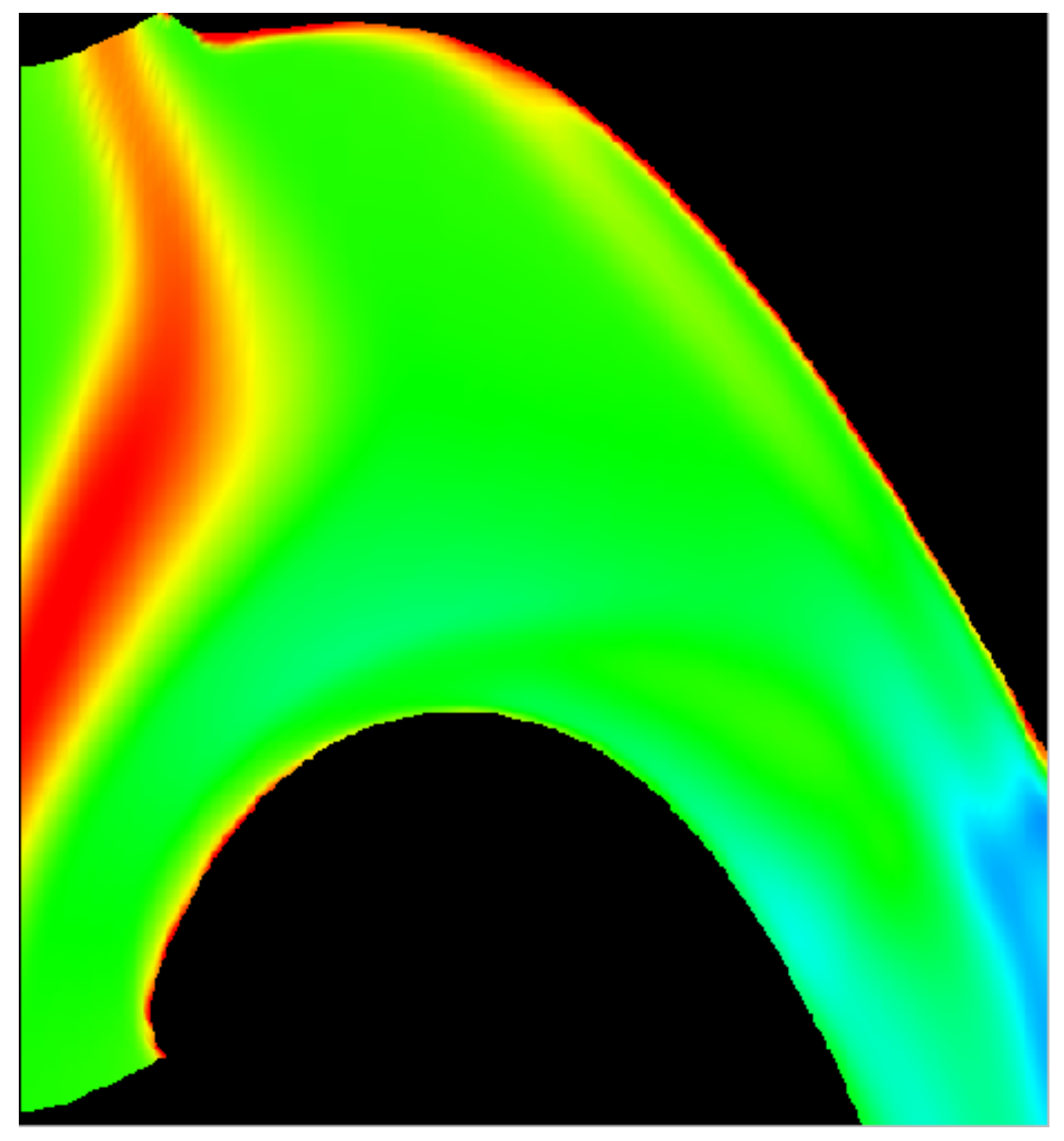

Figure 12. Density contours at midspan of rotor showing the high density incoming cold wakes and cooling flow. 


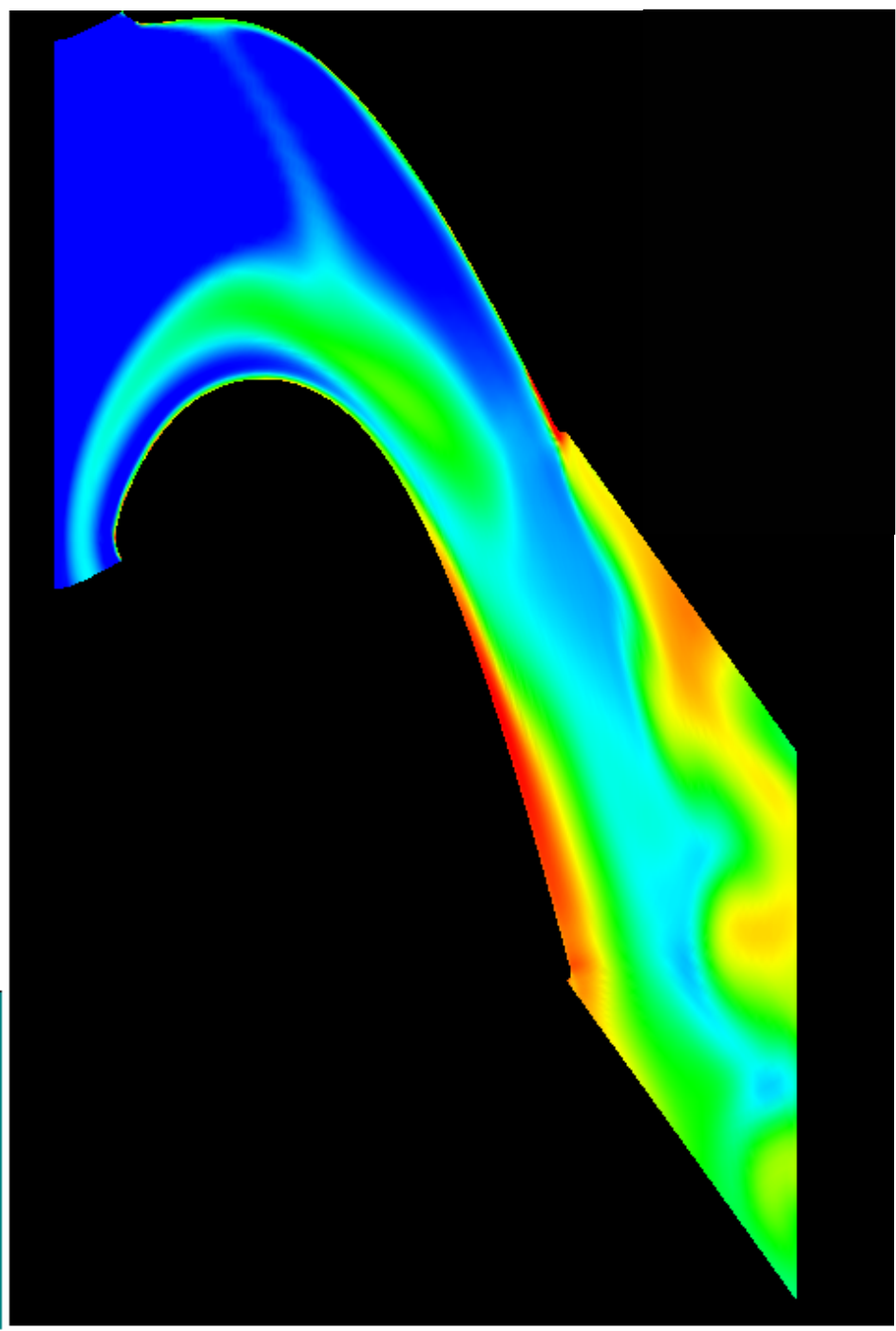

Figure 13. Variable $\gamma$ contour at midspan of cooled rotor. Minimum (blue) is 1.27 and maximum (red) is 1.31. 

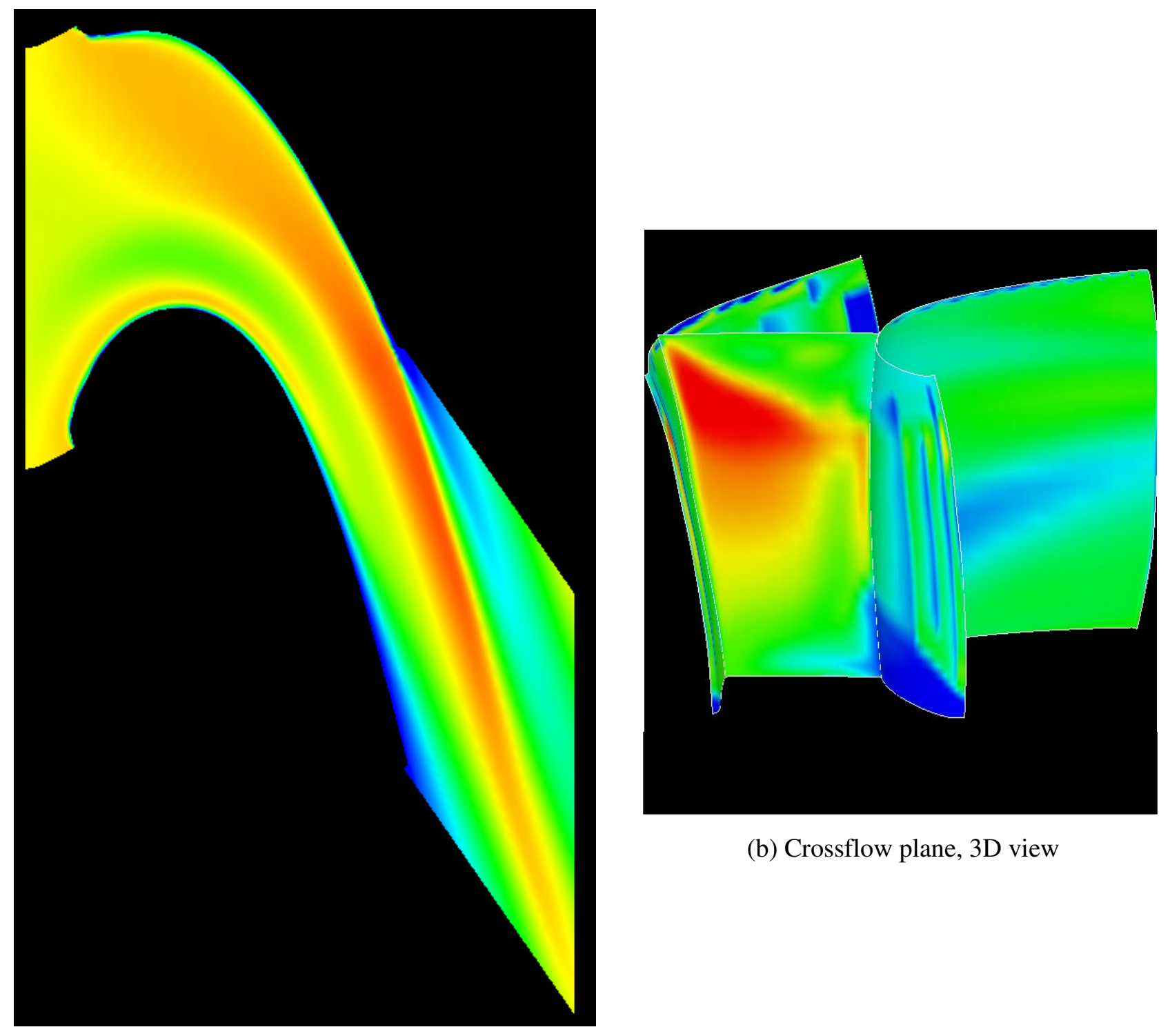

(b) Crossflow plane, 3D view

(a) Plane at midspan

Figure 14. Time-averaged Rothalpy contours showing the hot streak migration to the pressure side of the rotor blade. 


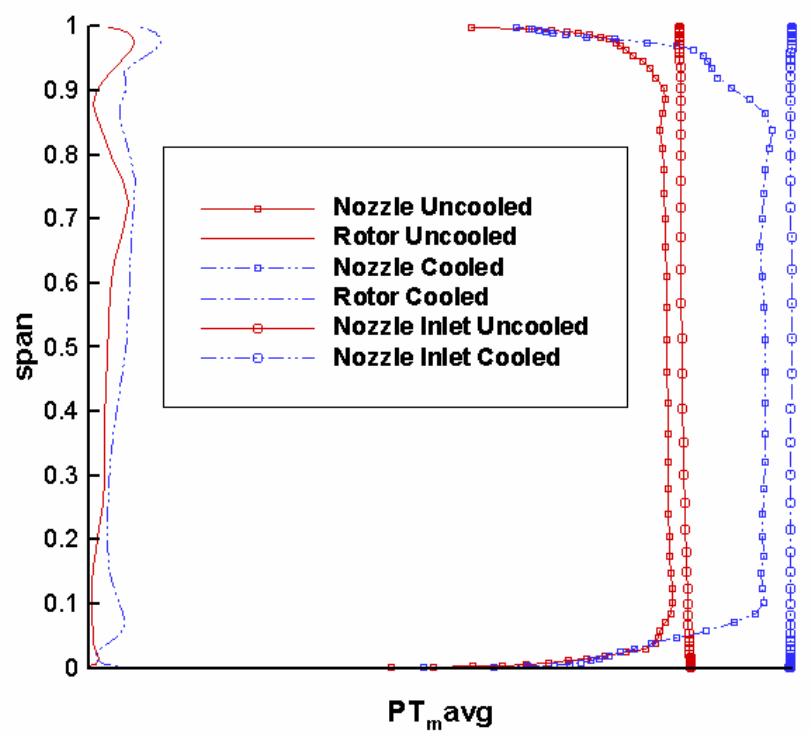

Figure 15. Total pressure profiles for the nozzle and rotor exits and the nozzle inlet.

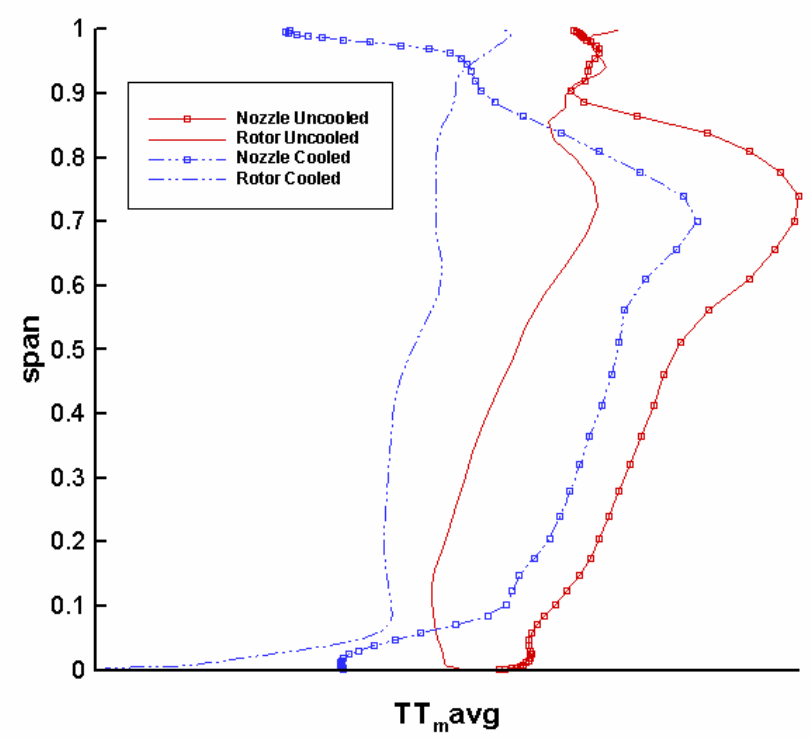

Figure 16. Total Temperature profiles for the nozzle and rotor exits.

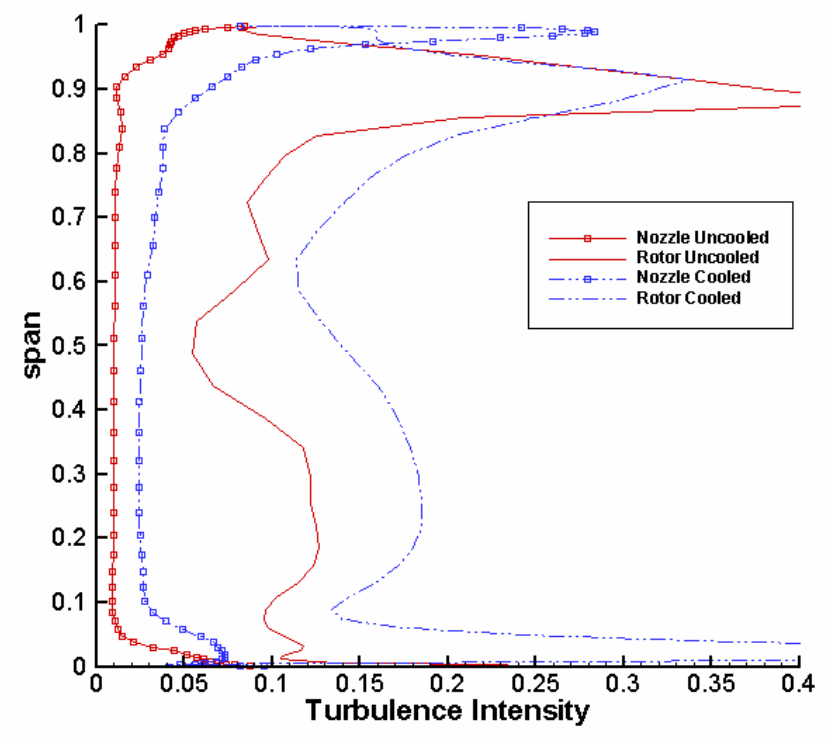

Figure 17. Turbulence intensity profiles for the nozzle and rotor exits. 


\begin{tabular}{|c|c|c|c|}
\hline \multicolumn{3}{|c|}{ REPORT DOCUMENTATION PAGE } & $\begin{array}{l}\text { Form Approved } \\
\text { OMB No. 0704-0188 }\end{array}$ \\
\hline \multicolumn{4}{|c|}{ 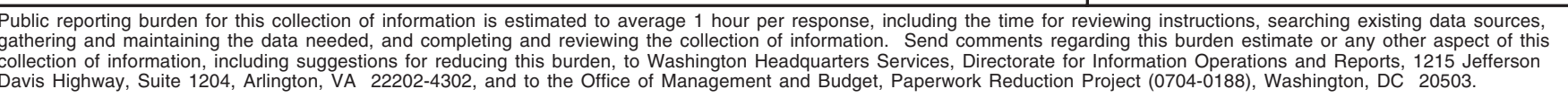 } \\
\hline 1. AGENCY USE ONLY (Leave blank) & \begin{tabular}{|} 
2. REPORT DATE \\
October 2004
\end{tabular} & 3. REPORT TYPE A & $\begin{array}{l}\text { D DATES COVERED } \\
\text { echnical Memorandum }\end{array}$ \\
\hline \multicolumn{3}{|c|}{$\begin{array}{l}\text { 4. TITLE AND SUBTITLE } \\
\text { Unsteady, Cooled Turbine Simulation Using a PC-Linux Analysis System }\end{array}$} & \multirow{2}{*}{$\begin{array}{l}\text { 5. FUNDING NUMBERS } \\
\text { WBS-22-714-09-12 }\end{array}$} \\
\hline \multicolumn{3}{|c|}{$\begin{array}{l}\text { 6. AUTHOR(S) } \\
\text { Michael G. List, Mark G. Turner, JenPing Chen, Michael G. Remotigue, } \\
\text { and Joseph P. Veres }\end{array}$} & \\
\hline \multicolumn{3}{|c|}{$\begin{array}{l}\text { 7. PERFORMING ORGANIZATION NAME(S) AND ADDRESS(ES) } \\
\text { National Aeronautics and Space Administration } \\
\text { John H. Glenn Research Center at Lewis Field } \\
\text { Cleveland, Ohio } 44135-3191\end{array}$} & $\begin{array}{l}\text { 8. PERFORMING ORGANIZATION } \\
\text { REPORT NUMBER }\end{array}$ \\
\hline \multicolumn{3}{|c|}{$\begin{array}{l}\text { 9. SPONSORING/MONITORING AGENCY NAME(S) AND ADDR } \\
\text { National Aeronautics and Space Administration } \\
\text { Washington, DC 20546-0001 }\end{array}$} & $\begin{array}{l}\text { 10. SPONSORING/MONITORING } \\
\text { AGENCY REPORT NUMBER } \\
\text { NASA TM-2004-212976 } \\
\text { AIAA-2004-0370 }\end{array}$ \\
\hline \multicolumn{4}{|c|}{$\begin{array}{l}\text { 11. SUPPLEMENTARY NOTES } \\
\text { Prepared for the 42nd Aerospace Sciences Meeting and Exhibit sponsored by the American Institute of Aeronautics } \\
\text { and Astronautics, Reno, Nevada, January 5-8, 2004. Michael G. List and Mark G. Turner, University of Cincinnati, } \\
\text { Cincinnati, Ohio 45220; JenPing Chen and Michael G. Remotigue, Mississippi State University, Starkville, Mississippi } \\
\text { 39762; and Joseph P. Veres, NASA Glenn Research Center. Responsible person, Joseph P. Veres, organization code 2900, } \\
\text { 216-433-2436. }\end{array}$} \\
\hline \multicolumn{3}{|c|}{$\begin{array}{l}\text { 12a. DISTRIBUTION/AVAILABILITY STATEMENT } \\
\text { Unclassified - Unlimited } \\
\text { Subject Categories: } 02,34 \text {, and } 07 \quad \text { Distribution: Nonstandard } \\
\text { Available electronically at http://gltrs.grc.nasa.gov } \\
\text { This publication is available from the NASA Center for AeroSpace Information, 301-621-0390. }\end{array}$} & 12b. DISTRIBUTION CODE \\
\hline
\end{tabular}

The fist stage of the high-pressure turbine (HPT) of the GE90 engine was simulated with a three-dimensional unsteady Navier-Sokes solver, MSU Turbo, which uses source terms to simulate the cooling flows. In addition to the solver, its pre-processor, GUMBO, and a post-processing and visualization tool, Turbomachinery Visual3 (TV3) were run in a Linux environment to carry out the simulation and analysis. The solver was run both with and without cooling. The introduction of cooling flow on the blade surfaces, case, and hub and its effects on both rotor-vane interaction as well the effects on the blades themselves were the principle motivations for this study. The studies of the cooling flow show the large amount of unsteadiness in the turbine and the corresponding hot streak migration phenomenon. This research on the GE90 turbomachinery has also led to a procedure for running unsteady, cooled turbine analysis on commodity PC's running the Linux operating system.

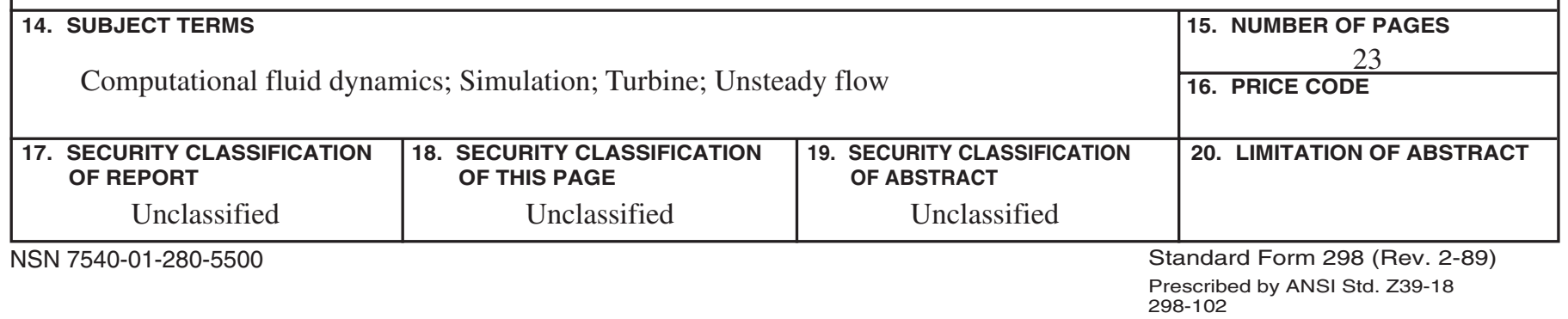



